\title{
Effectiveness Evaluation of Financing Platform Operation of Buildings Energy Saving Transformation Using ANP-Fuzzy in China: An Empirical Study
}

\author{
Handing Guo, Wanzhen Qiao * and Yuehong Zheng \\ School of Economics and Management, Tianjin Chengjian University, Tianjin 300384, China \\ * Correspondence: qiuchaoyue16@163.com
}

Received: 17 February 2020; Accepted: 21 March 2020; Published: 2 April 2020

\begin{abstract}
Building energy saving transformation is an inevitable requirement to achieve sustainable development, which can bring considerable economic, environmental, and social benefits. The key to healthy development of the market lies in the orderly operation of the financing platform. The effectiveness of the financing platform depends on scientific evaluation. Therefore, it is necessary to design a set of systematic and practical evaluation indicators for operational effectiveness of the buildings energy saving transformation financing platform, so as to provide reference for the effective operation of the financing platform, and provide measurement means for scholars to conduct quantitative research on the financing platform. This paper analyzes the effectiveness evaluation content for the financing platform operation of buildings energy saving transformation from the two levels of operation mechanism and operation subject behavior. Combined with the particularity of the financing platform of building energy saving transformation, the operational effectiveness evaluation index system of the financing platform is designed from three levels. The Analytic Network Process (ANP) method is applied to construct network structure, to describe element correlation, and to calculate index weight. The fuzzy comprehensive evaluation (Fuzzy) method was used to carry out quantitative evaluation of qualitative indicators. The Energy Performance Contracting (EPC) financing platform in Beijing was taken as an example to make an empirical analysis. The results show that the operational effectiveness evaluation system of the financing platform of buildings energy saving transformation constructed in this paper has certain practicability. In this evaluation system, scores of target consistency, the degree of information sharing among departments and coordination of operation mechanism are low. Finally, some policy suggestions are put forward to optimize financing platform of buildings energy saving transformation in China.
\end{abstract}

Keywords: buildings energy saving; transformation; financing platform; ANP; fuzzy comprehensive evaluation; policy optimization

\section{Introduction}

Nowadays, the world is facing environmental challenges due to excessive energy consumption, a sharp increase of carbon emissions, and climate warming, and low carbon economy has become the hot topic of global concern. As an artificial environment, buildings are an important part of meeting human beings' material and spiritual needs. However, the excessive pursuit of sensory enjoyment and uncontrolled development and construction of modern buildings not only alienates the natural connection and communication between humans and nature, but also brings a heavy burden to the environment and resources. According to statistics, more than $50 \%$ of materials obtained by humans from nature are used to construct various kinds of buildings and ancillary facilities, which consume about $50 \%$ of the global energy in the process of construction and use. Among the 
total environmental pollution, building-related air pollution, light pollution, and electromagnetic pollution accounted for $34 \%$, buildings waste accounts for $40 \%$ of the total waste generated by human activities [1]. In developing countries, the surge of buildings has also led to land encroachment and ecological damage [2]. Building energy saving transformation is incorporated in the general WEF Nexus structure [3], which is conducive to reducing energy consumption, saving the use of land resources and water sources, reducing the pollution of soil, water and air, improving the quality of people's lives, promoting harmony between human beings and nature, and achieving sustainable development of construction industry.

At present, the international market of building energy saving transformation mostly adopts EPC as its main operation mode [2]. There are owner financing, ESCO financing, and third-party financing available in EPC financing [4]. However, problems such as imperfect systems, imperfect governance structures and a lack of supervision are common, which cannot give full play to the role of financing in the actual operation process. In addition, ESCO is a kind of profit-making professional company that provides services such as energy utilization status diagnosis, energy-saving project design, financing, transformation, operation management, etc., and provides specialized energy-saving technical services. An important problem that cannot be ignored is that EPC is very important for transferring investment opportunities, but most of the investment in the buildings energy saving transformation market is still self-financing for owners and energy services companies (ESCO), such as owners' personal savings or ESCO's own balance sheet. Therefore, it is difficult for self-owned funds to meet their own development needs, and this type of financing cannot achieve investment growth. An open and transparent financing platform is indispensable to enhance the confidence and ability of market subjects in building energy saving transformation and encourage more extensive investment. However, there is still a lack of an objective and effective evaluation mechanism for the financing platform of building energy saving transformation in academia. Deeply understanding the operation effect of financing platform and checking whether it meets anticipated goal of the buildings energy saving transformation project will help to measure the actual benefit and improvement space of the financing platform for buildings energy saving transformation, help to overcome financing difficulties and further improve target management plan. Buildings energy saving transformation has the characteristics of various projects, different investment scales, strong professionalism, and difficult to copy project evaluation models. Solar power in buildings is augmented by its nature as a public goods [5]. In addition, the transformation object involves tall buildings [5], city morphology [6], porous building materials [7], construction project impact [8] and other special circumstances, bank loan experience is difficult to reuse, loan risk is difficult to assess, and the cost of tracking and approval is too high, which leads to financing difficulties of ESCO, restrains the enthusiasm of subjects, and slow market development. In developing countries, ESCO is faced with many difficulties, such as imperfect laws, lack of technology and talents, huge financial pressure and poor credit evaluation system [9]. In order to solve the financing dilemma of buildings energy saving transformation projects, developed countries have implemented measures to optimize the financing environment, mainly from the two aspects of deepening existing financing system and innovative financing mode. The European Union (EU) provides financial subsidies, tax incentives and scientific research support in finance, and sets up green loans, zero-interest loans and preferential loans in bank loans [10]. For example, the German Renaissance Credit Bank gives discount loans, interest-free loans or low-interest loans for energy saving investment and energy saving technology opening projects, and the interest rate of energy saving transformation loans is $0.5 \%$ lower than that of ordinary commercial banks [11-13]. The French government reduced personal income tax on investment in energy saving and implemented zero-interest loans [14]. Developed countries innovate their financing modes by setting up special funds and EPC financing modes, such as the United State Energy Program (SEP) Funds [15], and German Kreditanstalt Fuer Wiederaufbau (KFW) Fund [16].

Up to now, scholars have conducted extensive and continuous research on the policies, risks, benefits, obstacles, and modes of financing for buildings energy saving transformation. Wang [17] 
believed that a stable incentive policy could effectively reduce financing risk and cost of energy saving transformation. Bjorneboe [18] pointed out that there were many problems in financing process of buildings energy saving transformation, such as information, credit, guarantee and so on, which hinder the market development. Lee [2] found that ESCO faced financing obstacles such as insufficient state support, insufficient bank awareness, and imperfect information disclosure mechanism. Kragh [19] believed that a standardized financing platform could help achieve standardization of energy saving products. Gillich [20] explored the obstacles to the development of buildings energy saving transformation market in terms of financing difficulties, high management fees and high transaction fees. Economidou [21] believed that energy saving service market lacks strong legal means to restrain owners' behavior, and specialized financing platform is an effective way to strengthen the confidence of other subjects. Marino [22] revealed that ESCO uses financing platform to convert future earnings from energy saving transformation into financing collateral, but its pursuit of maximum benefits affects the normal operation of platform. Robinson [23] emphasized that credit issue is the core of energy saving service industry to get rid of financing dilemma. This is because EPC generally has credit risk that the owner cannot meet the energy saving share.

The existing research mainly focuses on the financing influencing factors of buildings energy saving transformation, and lacks the attention to operational effectiveness of financing platform. Based on this, this paper takes market operation effectiveness of buildings energy saving transformation as the breakthrough point, uses ANP-Fuzzy method to make theoretical and practical exploration on evaluation index system and evaluation method of the operation effectiveness of buildings energy saving transformation financing platform. This paper aims to introduce an integrated method using ANP-Fuzzy to deal with the key strategic variables of financing platform operation of buildings energy saving transformation. In addition, the evaluation index system of financing platform operation is constructed, and its feasibility and operability are verified. It provides theoretical reference for relevant scholars to conduct quantitative research on financing platform operation of buildings energy saving transformation, and provides practical reference for government to formulate financing planning for buildings energy saving transformation.

The remainder of this paper is structured as follows: Section 2 introduces ANP-Fuzzy method. Section 3 constructs the effectiveness evaluation index system. Section 4 is a case study. Section 5 further discusses the result.

\section{Methods}

The ANP-Fuzzy method is a comprehensive evaluation method that combines the network hierarchy analysis method with the fuzzy level evaluation method. The ANP method can reflect the interaction between system elements through a network structure in a complex decision system [24]. Fuzzy comprehensive evaluation can quantitatively evaluate qualitative indicators through fuzzy mathematics membership theory in complex decision-making [25]. The method from classification refinement evaluation to overall comprehensive evaluation, and the overall evaluation results are finally obtained after multi-level evaluation.

\subsection{Construction of ANP Model}

ANP is a new practical decision-making method based on Analytic Hierarchy Process (AHP) proposed by professor Saaty in 1990s. AHP expresses the relationship of elements in the system with a network structure rather than a simple hierarchical structure. Elements in the network layer can influence and dominate each other [26]. ANP is the improvement and extension of AHP. Both of them use 1-9 scale method to measure the importance of elements, and need to construct judgment matrix, solve the eigenvector after consistency detection, and finally determine the scheme order. However, the network structure of ANP is more complex than AHP. ANP has not only hierarchical structure, but also internal dependence and feedback structure. Although both are particular cases of Markov Chains, where the "Markovization" process leads to a more robust resolution of ANP priorities when 
the selections are close, i.e., increased sensitivity. Therefore, ANP can more accurately describe the relationship between objective things [27], and it is a more effective decision-making method.

\subsubsection{Constructing ANP-Typical Structure}

The construction of ANP model firstly analyses the mutual influence among evaluation indexes, secondly constructs the ANP typical structure, and finally describes the correlation among elements. The ANP typical structure includes control layer and network layer [28]. The control layer, also known as the control criterion layer, is the highest criterion layer, and all criteria in the control layer are independent of each other [29]. The network layer consists of multiple element sets, which are not mutually dependent, but interrelated [30]. Figure 1 indicates the typical ANP structure.

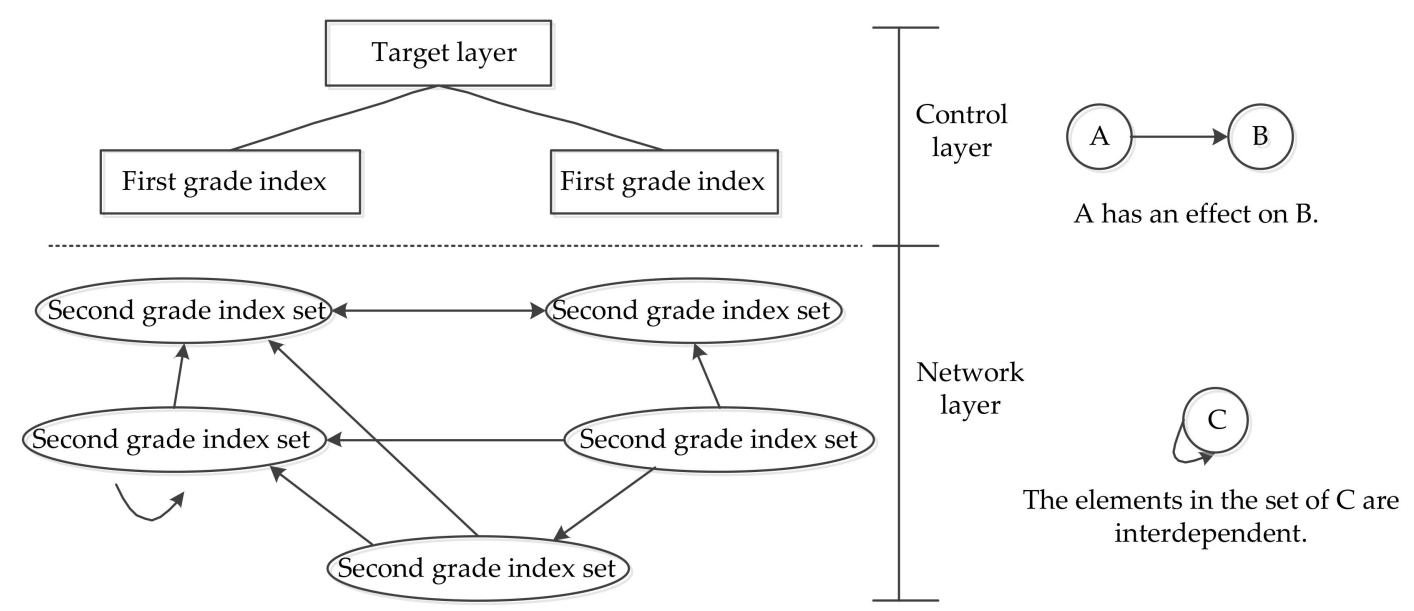

Figure 1. Typical ANP structure.

\subsubsection{Determining Index Weight}

The core work of ANP empowerment is to solve super matrix [31]. This is a complicated calculation process. Manual operation is very difficult. Super Decision (SD) software can solve this problem. The specific implementation steps are as follows:

1. Determine judgment matrix, construct initial super matrix and weighted super matrix. Based on the control layer elements, the structure of network layer is compared by using 1-9 scales (Table 1) Thus the judgment matrix and the eigenvector are formed [32,33].

2. According to $\mathrm{CR}=\mathrm{CI} / \mathrm{RI}$, the consistency test of the judgment matrix is tested. If $\mathrm{CR} \leq 0.1$, the judgment matrix passes the consistency test. If $C R \geq 0.1$, the judgment matrix is inconsistent and should be revised and adjusted.

3. The eigenvector generates the local weight vector matrix in matrix form, and finally forms initial super matrix.

4. Computing weighted super matrix.

5. Calculating limit super matrix. 
Table 1. 1-9 Scaling method in judgment matrix.

\begin{tabular}{cc}
\hline Scale & Meaning Description \\
\hline 1 & $i$ and $j$ are equally important \\
3 & $i$ is slightly more important than $j$ \\
7 & $i$ is obviously more important than $j$ \\
9 & $i$ is strongly important than $j$ \\
& $i$ is extremely important than $j$ \\
$1,1 / 3,1 / 5,1 / 7,1 / 9$ & If the importance ratio of $i$ to $j$ is one of the above values, then the \\
& importance ratio of $j$ to $i$ is the reciprocal of $i$. \\
\hline
\end{tabular}

\subsection{Construction of Fuzzy Comprehensive Evaluation Model}

\subsubsection{Establish Evaluation Object Sets and Factor Sets}

Let the evaluation object set be $X=\left\{\chi_{1}, \chi_{2}, \cdots \chi_{i}\right\}$, the evaluation indicators set be $U=$ $\left\{U_{1}, U_{2} \cdots U_{m}\right\}$, break down each indicator $U_{i}$ into several factors $\mu_{i j}\left(U_{i}=\left\{\mu_{i 1}, \mu_{i 2}, \cdots \mu_{i m}\right\}\right), \mu_{i j}$ represents the $j$-th factor of the $i$-th indicator $(\mathrm{i}=1,2, \cdots \mathrm{m} ; \mathrm{j}=1,2, \cdots \mathrm{n})$.

\subsubsection{Create Comment Sets}

Assuming that there are $\mathrm{h}$ possible results of the total evaluation, the set of evaluation grades can be expressed as $V=\left\{v_{1}, v_{2}, \cdots v_{h}\right\}, v_{k}(k=1,2, \cdots, h)$ represents the total evaluation result of the $h$-th possibility.

\subsubsection{Establish Weight Set}

The weight indicates the importance of each indicator in the indicator system [34]. Multi-index comprehensive evaluation generally adopts subjective empowerment, objective empowerment or a combination of the two methods [35]. Suppose that the indicator weight $U_{i}$ is $A_{i}\left(A_{i}=\left\{a_{i 1}, a_{i 2}, \cdots, a_{i n}\right\}\right)$, where $a_{i j}$ is the weight within the group of $U_{i}$ relative to $\mu_{i j}$, and $\sum_{i}^{n} a_{i j}=1$.

\subsubsection{First-Level Fuzzy Comprehensive Evaluation}

First, each factor $U_{i}$ was evaluated separately according to the evaluation set to determine the membership degree of each indicator to the evaluation grade, and obtained the relational matrix: $R_{i}=\left[\begin{array}{cccc}r_{i 11} & r_{i 12} & \cdots & r_{i 1 h} \\ r_{i 21} & r_{i 21} & \cdots & r_{i 2 h} \\ \vdots & \vdots & \ddots & \vdots \\ r_{i n 1} & r_{i n 2} & \cdots & r_{i n h}\end{array}\right](1,2, \cdots m)$ which $r_{i j k}$ represents the membership degree of indicator $U_{i}$ to comment $v_{k}$ from factor $u_{i j}$. The performance of indicator $U_{i}$ in factoris $u_{i j}$ described by fuzzy vector $r_{i j}$.

Secondly, the weight vector $A_{i}=\left\{a_{i 1}, a_{i 2}, \cdots, a_{i n}\right\}$ of the index $U_{i}$ is multiplied by the relationship matrix $R_{i}$ to obtain the comprehensive evaluation result vector of the index $U_{i}$.

$$
B_{i}=A_{i} \times R_{i}=\left(a_{i 1}, a_{i 2}, \cdots, a_{i n}\right)\left[\begin{array}{cccc}
r_{i 11} & r_{i 12} & \cdots & r_{i 1 h} \\
r_{i 21} & r_{i 21} & \cdots & r_{i 2 h} \\
\vdots & \vdots & \ddots & \vdots \\
r_{i n 1} & r_{i n 2} & \cdots & r_{i n h}
\end{array}\right]=\left(b_{i 1}, b_{i 2}, \cdots b_{i n}\right)
$$

\subsubsection{Multi-Level Fuzzy Comprehensive Evaluation}

It is assumed that the single index fuzzy evaluation is the first level fuzzy comprehensive evaluation, and the comprehensive evaluation matrix of second level fuzzy comprehensive evaluation is the vector composition matrix of the results of each level fuzzy comprehensive evaluation [36,37]. 
$\mathrm{R}=\left[\begin{array}{c}B_{1} \\ B_{2} \\ \cdots \\ B_{m}\end{array}\right]=\left[\begin{array}{c}A_{1} \cdot R_{1} \\ A_{2} \cdot R_{2} \\ \cdots \\ A_{m} \cdot R_{m}\end{array}\right]=\left(r_{i k}\right) m \times h, r_{i k}=b_{i k}(i=1,2, \cdots m ; k=1,2, \cdots, h)$. The vector of the result of the second-level fuzzy comprehensive evaluation is the product of the above index weight vector and the second-level fuzzy comprehensive evaluation matrix, that is $\mathrm{B}=\mathrm{A} \cdot \mathrm{R}=$ $\mathrm{A}\left[\begin{array}{c}A_{1} \cdot R_{1} \\ A_{2} \cdot R_{2} \\ \cdots \\ A_{m} \cdot R_{m}\end{array}\right]=\left(b_{1}, b_{2}, \cdots, b_{h}\right)$. Similarly, the results of multi-level fuzzy comprehensive evaluation are obtained.

\subsubsection{Comprehensive Judgment of Evaluation Result}

Because fuzzy comprehensive evaluation is a vector, for the multi-level fuzzy comprehensive evaluation involving multiple indexes, the evaluation result vector is generally uniformization, in order to facilitate the comparison of evaluation results and make full use of information brought by the result vector [38]. That is, assigning values to each evaluation grade in the comment set, and then multiply them by component vectors in result vector B to get the weighted value. $C=\frac{\sum_{k=1}^{h} b_{k}^{p} c_{k}}{\sum_{k=1}^{h} b_{k}^{p}}$. P is the undetermined coefficient and the general value is 1.

\section{Construction of Effectiveness Evaluation Index System of the Financing Platform Operation for Buildings Energy Saving Transformation}

\subsection{Principles of Index System Construction}

(1) Scientific and reasonable. This principle requires a scientific generalization hierarchy, reflecting as much as possible the key content of the evaluation system, with strong representation and large amount of information, so as to reasonably describe, analyze and evaluate key issues [39,40].

(2) Systematic. This principle requires that the index system reflect various factors that may have an impact on the evaluation object. In addition, the refinement of evaluation indicators must be logical, statistical indicators can complement each other, lower indicators and higher indicators have levels, so as to achieve a balanced and unified evaluation system

(3) Reliability. This principle requires that the evaluation index system must conform to objective facts, and each index can be easily measured and calculated [41]. Financial indicators should be supported by authoritative data and non-financial indicators should be scientifically determined, such as through scientific research or expert evaluation

(4) Combination of quantitative and qualitative indicators. This principle requires that the selection of evaluation indicators include not only quantitative analysis indicators, but also qualitative analysis indicators, while minimizing the impact of subjective factors [42].

(5) Testability. This principle requires that the index system be concise and easy to understand and data collection, evaluation results can be obtained more quickly. In order to ensure the comparability between indicators, the same type of indicators need to be unified sources, different types of indicators can be quantified, easy to calculate and compare [43].

\subsection{Analysis of Evaluation Content}

The operational effectiveness of a financing platform for buildings energy saving transformation depends on the extent to which it improves the financing efficiency of buildings energy saving transformation project and promotes the financing practice of buildings energy saving transformation. In order to solve the difficulty of project financing, a comprehensive investigation of the operating 
benefits and efficiency of the financing platform is carried out. Compared with the general financing platform, the main difference between the financing platforms for buildings energy saving transformation is the diversity of financing subjects and the complexity of the financing implementation process [44,45]. Building particularities play a role in platform operation and a pre-entry building analysis based on BIM/BMS would be useful $[46,47]$. Therefore, drawing on the relevant theories of general financing platform evaluation, considering the particularity of buildings energy saving transformation financing platform [48-50], the connotation of the operational effectiveness of buildings energy saving transformation financing platform includes two meanings: the effectiveness of the operational mechanism and the effectiveness of the operational subject. Specifically, the effectiveness of the operational mechanism implementation mainly examines the degree of the system's operational objectives and the degree of advancement of buildings energy saving transformation market development. The comprehensiveness of the operational mechanism, that is, the degree of cooperation and feedback between various operational mechanisms. Coordination of operational processes, that is, linkage of various links in the operation process. The compatibility of the operating mechanism with the market environment, that is, the update and adjustment of the operating mechanism market development, and the policy differences for different market environment changes. The effectiveness of operation subject behavior mainly examines the enthusiasm of the energy-using unit, the development of the ESCO, and input and output of the investor's participation in the financing platform. The development of ESCO, that is, the extent to which ESCO's economic strength, technical level, and reputation have an impact on the platform operational efficiency. Investor enthusiasm, that is, the degree of active efforts of market supply entities. The cooperation between the subjects, that is, the cooperation between the subjects is good or not.

\subsection{Construction of Evaluation Index System}

In order to ensure that the evaluation results can effectively reflect the objective reality, this study adheres to the system's comprehensive and scientific principles, according to the content analysis of the effectiveness evaluation of the financing platform to sort out the existing research results. Through sorting out, classifying, deleting, and refining the evaluation indexes, we preliminarily obtain the effectiveness evaluation index system structure of financing platform. On this basis, the expert consultation method is used to consult 10 experts from enterprises, building energy saving consultation institutions and universities, determining the content of evaluation index system and ultimately to construct an effectiveness evaluation index system structure of buildings energy saving transformation financing platform is shown in Table 2. 
Table 2. Evaluation index system structure.

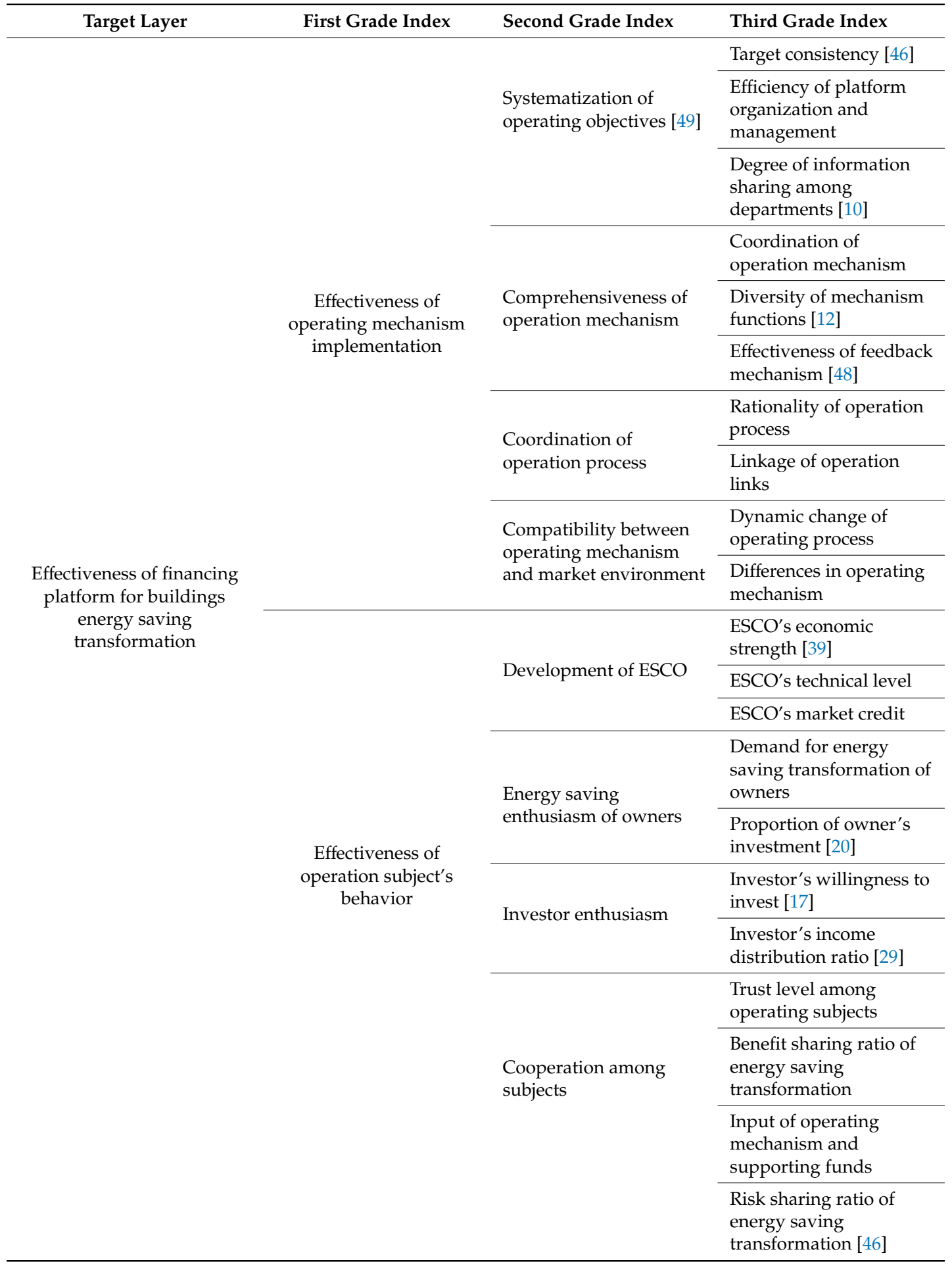

\section{Case Study}

Energy Performance Contracting Financing Trading Platform in Beijing was officially launched on June 6, 2010. It is the first platform to publicly list EPC as a trading category in the world. With the help of third-party investment, this platform breaks the bottleneck of insufficient self-owned funds and long turnover period of ESCO, connects energy saving service industry with financial industry, integrates relevant resources, and fully exchanges project information and investor information on the platform through value-added services. This platform is an important measure to accelerate EPC 
by using market mechanism, and a powerful tool to promote energy saving and emission reduction by means of financial innovation. It is of great significance to develop the buildings energy saving transformation market, and build an environment-friendly and resource-conserving society. In the development process of nearly ten years, the platform has made some achievements. However, from the perspective of operational effectiveness of the platform, due to the late establishment, few listing and trading projects, and the lack of experience in operation of the platform, the comprehensive benefits of the financing platform are restricted. One problem that cannot be ignored is that due to the lack of a sound regulatory mechanism and tax mechanism in the market, the integrity environment within the platform is poor, which directly affects normal operation of the financing platform. Therefore, based on the contract amount concluded within the platform from June 2010 to June 2019, this paper evaluates operational effectiveness of financing platform for buildings energy saving transformation.

\subsection{ANP Structure for Effectiveness Evaluation of Financing Platform Operation}

In the process of constructing the indicator system, only the evaluation indicators are identified. To establish the ANP model, it is necessary to study the feedback and dependence between the evaluation indicators [51]. The correlation of the research indicators was obtained in the form of a two-dimensional table through expert questionnaires. By analyzing the mutual influence relationship among each evaluation index for financing platform operational effectiveness of buildings energy saving transformation, the ANP typical structure is constructed and the elemental relevance is described [52], as shown as in Figure 2.

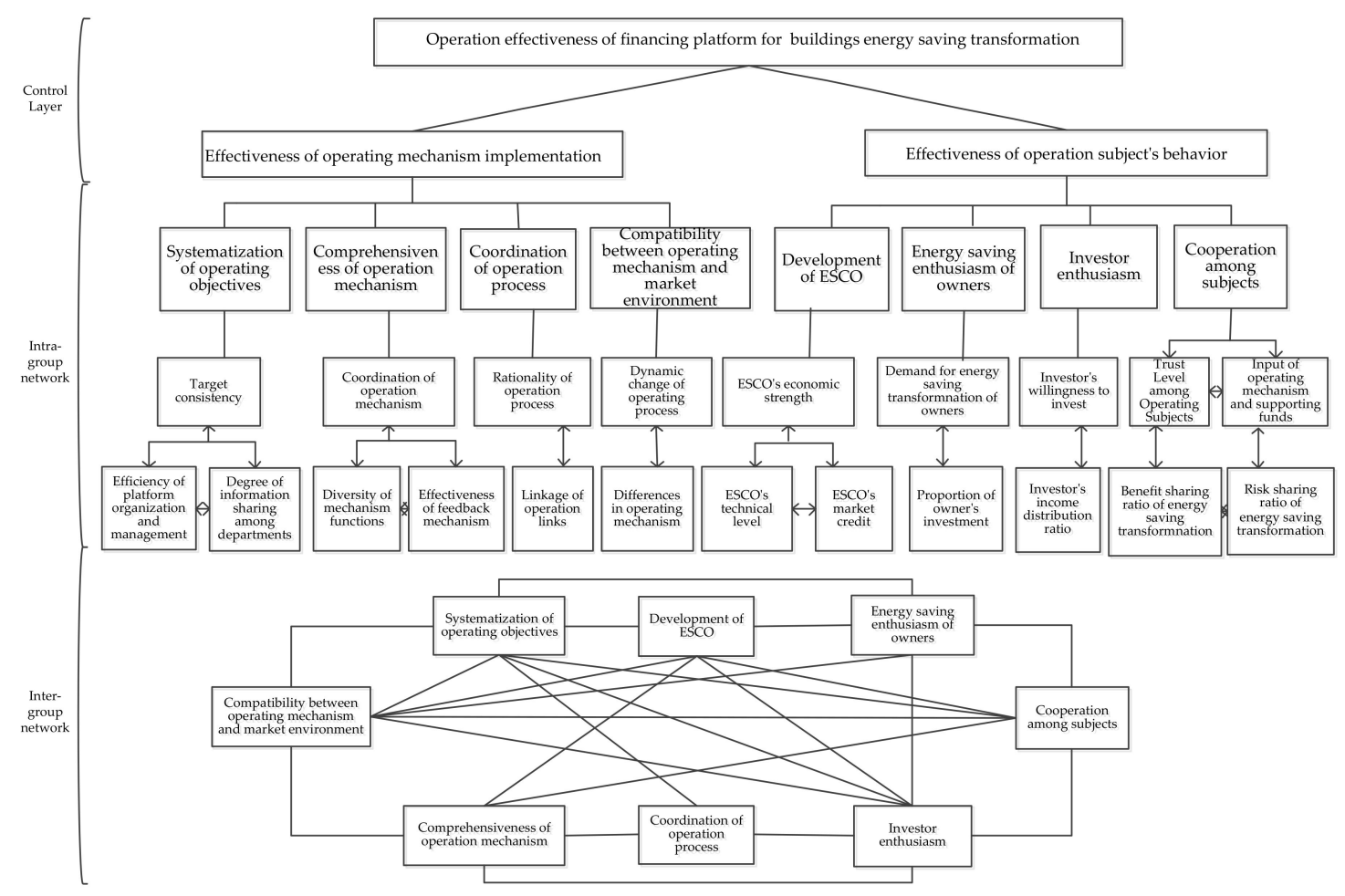

Figure 2. ANP structure.

\subsection{Empowerment of Evaluation Indicators Based on ANP}

The relationship between each group and each node in the ANP structure is input into the SD software, and ten industry experts are invited to score the importance of each index according to the 1-9 scale method, and the score results are sorted and input into the software (Figure 3). The ten experts in this paper are composed of six professors who are engaged in the research of building energy saving in universities and four staff members who have more than five years' experience in energy 
saving service companies. Using the software to obtain super matrix, the matrix consistency test result is $0.0960<0.1$, indicating that the super matrix has good consistency, as shown in Figure 4 .

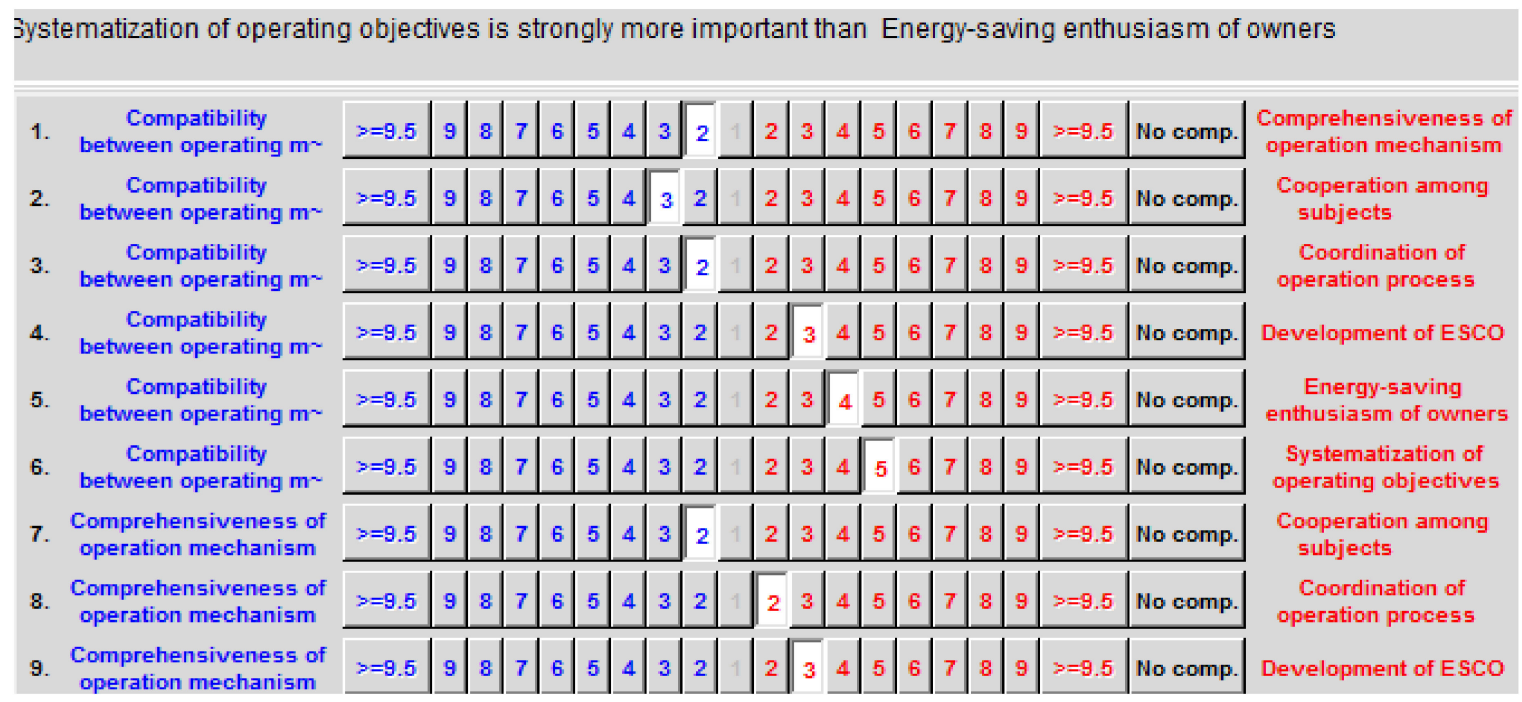

Figure 3. An example of SD software scoring interface.

\begin{tabular}{|c|r|}
\multicolumn{2}{|c}{ The inconsistency index is 0.0628 . It is } \\
desirable to have a value of less than 0.1 \\
\hline $\begin{array}{c}\text { Compatibility between } \\
\text { operating mechanism and } ~\end{array}$ & 0.081744 \\
\hline $\begin{array}{c}\text { Comprehensiveness of } \\
\text { operation mechanism }\end{array}$ & 0.050922 \\
\hline $\begin{array}{c}\text { Cooperation among } \\
\text { subjects }\end{array}$ & 0.038672 \\
\hline $\begin{array}{c}\text { Coordination of operation } \\
\text { process }\end{array}$ & 0.067305 \\
\hline $\begin{array}{c}\text { Development of ESco } \\
\text { Energy-saving enthusiasm } \\
\text { of owners }\end{array}$ & 0.126699 \\
\hline $\begin{array}{c}\text { Systematization of } \\
\text { operating objectives }\end{array}$ & 0.207843 \\
\hline
\end{tabular}

Figure 4. Consistency test results of SD software.

The SD software is used to obtain the objective weight (Figure 5), and the weights in group are obtained by using the formula: Intra-group weight = (the objective weight of the third grade index under the second grade index)/(the sum of all the three grade index of the second grade index) [53]. The weight results are sorted and the final calculation results of the index weights at all levels are obtained in Table 3. 
Here are the priorities.

\begin{tabular}{|c|c|c|c|}
\hline Icon & Name & $\overline{\text { Normalized by Cluster }}$ & $\longdiv { \text { Limiting } }$ \\
\hline No Icon & Target consistency & 0.30656 & 0.040751 \\
\hline No Icon & \begin{tabular}{|c|} 
Efficiency of platform \\
organization and managem
\end{tabular} & 0.34479 & 0.045832 \\
\hline No Icon & \begin{tabular}{|c|} 
Degree of information \\
sharing among departments
\end{tabular} & 0.34865 & 0.046345 \\
\hline No Icon & $\begin{array}{l}\text { Coordination of operation } \\
\text { mechanism }\end{array}$ & 0.33381 & 0.044373 \\
\hline No Icon & $\begin{array}{l}\text { Diversity of mechanism } \\
\text { functions }\end{array}$ & 0.32361 & 0.043017 \\
\hline No Icon & $\begin{array}{l}\text { Effectiveness of feedback } \\
\text { mechanism }\end{array}$ & 0.34258 & 0.045539 \\
\hline No Icon & $\begin{array}{l}\text { Rationality of operation } \\
\text { process }\end{array}$ & 0.56502 & 0.075107 \\
\hline No Icon & $\begin{array}{l}\text { Linkage of operation } \\
\text { links }\end{array}$ & 0.43498 & 0.057821 \\
\hline No Icon & $\begin{array}{l}\text { Dynamic change of } \\
\text { operating process }\end{array}$ & 0.51772 & 0.068820 \\
\hline No Icon & $\begin{array}{l}\text { Differences in operating } \\
\text { mechanism }\end{array}$ & 0.48228 & 0.064108 \\
\hline No Icon & ESCO's economic strength & 0.34042 & 0.026861 \\
\hline No Icon & ESCO's technical level & 0.34042 & 0.026861 \\
\hline No Icon & ESCO's market credit & 0.31916 & 0.025184 \\
\hline No Icon & $\begin{array}{l}\text { Demand for energy saving } \\
\text { reconstruction of owners }\end{array}$ & 0.48198 & 0.064069 \\
\hline No Icon & $\begin{array}{l}\text { Proportion of owner's } \\
\text { investment }\end{array}$ & 0.51802 & 0.068860 \\
\hline No Icon & $\begin{array}{l}\text { Investor's willingness to } \\
\text { invest }\end{array}$ & 0.50000 & 0.061762 \\
\hline
\end{tabular}

Figure 5. Calculating results of third grade index weight of SD software. 
Table 3. The effectiveness evaluation index weights.

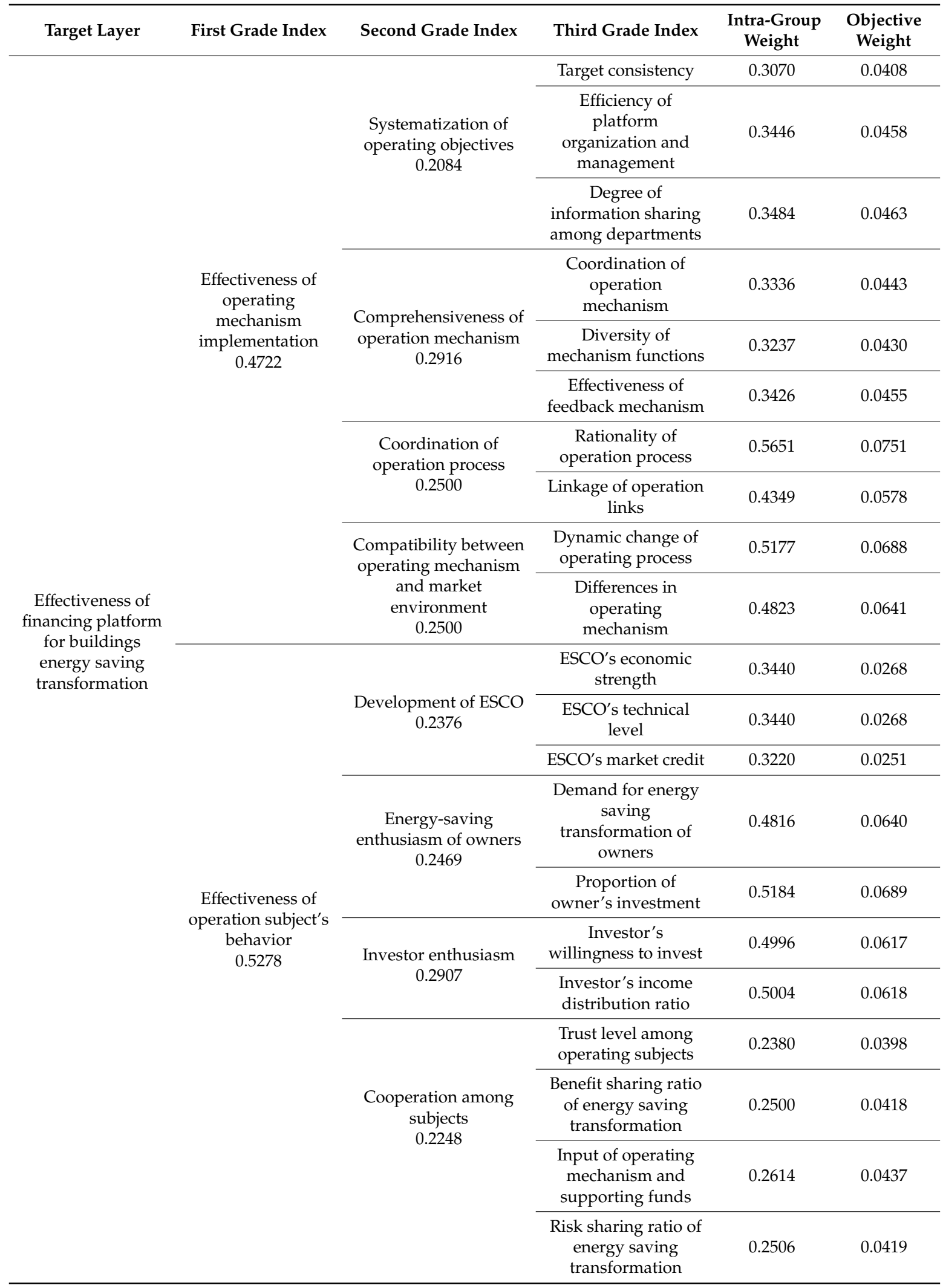




\subsection{Fuzzy Comprehensive Evaluation}

\subsubsection{Establish Factor Sets and Weight Sets for Evaluation}

Build a set of factors $U=\left\{u_{1}, u_{2}, \cdots u_{21}\right\}$ divide $U$ into two subsets of $U_{1}, U_{2} \cdot U_{1}$ indicates the effectiveness of operating mechanism implementation, and $U_{2}$ indicates the effectiveness of operation subject's behavior. Among them, $U_{1}=\left\{U_{11}, U_{12}, U_{13}, U_{14}\right\} U_{2}=\left\{U_{21}, U_{22}, U_{23}, U_{24}\right\} U_{11}$, $U_{12}, U_{13}, U_{14}, U_{21}, U_{22}, U_{23}, U_{24}$, are second grade index. $U_{11}=\left\{u_{1}, u_{2}, u_{3}\right\} U_{12}=$ $\left\{u_{4}, u_{5}, u_{6}\right\} U_{13}=\left\{u_{7}, u_{8}\right\} U_{14}=\left\{u_{9}, u_{10}\right\} U_{21}=\left\{u_{11}, u_{12}\right\} U_{22}=\left\{u_{13}, u_{14}, u_{15}\right\} U_{23}=$ $\left\{u_{16}, u_{17}\right\} U_{24}=\left\{u_{18}, u_{19}, u_{20}, u_{21}\right\}$. Among them, $u_{i}(\mathrm{i}=1,2, \cdots 21)$ is first grade index.

According to the results of the index weights obtained above, the evaluation index weights are obtained: $\mathrm{W}=(0.4722,0.5278) W_{1}=(0.2084,0.2916,0.2500,0.2500) W_{2}=$ $(0.2376,0.2469,0.2907,0.2248) \quad W_{11}=\left(\begin{array}{lllllll}0.307 & 0, & 0.344 & 6, & 0.348 & 4\end{array}\right) \quad W_{12}=$

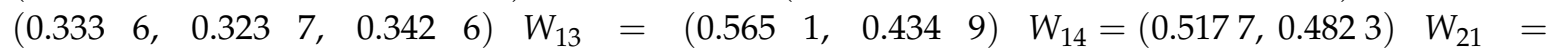

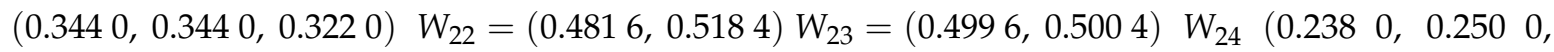
$0.2614,0.2506)$.

\subsubsection{Establish a Platform Operation Effectiveness Review Set}

The evaluation object of the review set is the operation effect of the financing platform for the energy saving transformation. Hypothesis commentary set is $\mathrm{V}$ \{very good, good, average, poor, very poor\}. The review set can reflect the platform effectiveness [54].

\subsubsection{First-Level Fuzzy Comprehensive Evaluation}

Inviting 10 industry experts to be divided into operational efficiency indicators of the energy saving transformation financing platforms, score the results, and obtain the following single-factor fuzzy evaluation matrix:

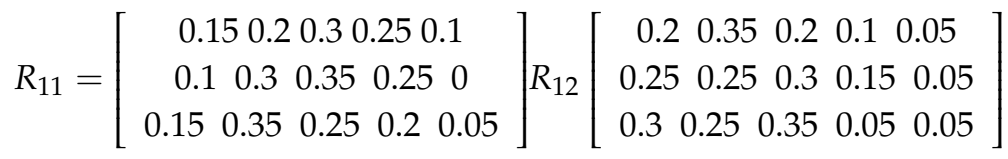

$$
\begin{aligned}
& R_{13}=\left[\begin{array}{lllll}
0.15 & 0.2 & 0.35 & 0.2 & 0.1 \\
0.1 & 0.2 & 0.3 & 0.25 & 0.15
\end{array}\right] R_{14}=\left[\begin{array}{ccccc}
0.2 & 0.2 & 0.35 & 0.2 & 0.05 \\
0.3 & 0.25 & 0.3 & 0.15 & 0
\end{array}\right] \\
& R_{21}=\left[\begin{array}{lllll}
0.3 & 0.35 & 0.2 & 0.1 & 0.05 \\
0.2 & 0.25 & 0.3 & 0.1 & 0.15
\end{array}\right] R_{22}=\left[\begin{array}{ccccc}
0.1 & 0.25 & 0.3 & 0.3 & 0.05 \\
0.25 & 0.15 & 0.4 & 0.1 & 0.1 \\
0.05 & 0.25 & 0.3 & 0.25 & 0.15
\end{array}\right] \\
& R_{23}=\left[\begin{array}{ccccc}
0.35 & 0.25 & 0.2 & 0.15 & 0.05 \\
0.15 & 0.2 & 0.3 & 0.25 & 0.1
\end{array}\right] R_{24}=\left[\begin{array}{ccccc}
0.3 & 0.35 & 0.2 & 0.1 & 0.05 \\
0.25 & 0.25 & 0.3 & 0.1 & 0.1 \\
0.2 & 0.3 & 0.15 & 0.15 & 0.2 \\
0.3 & 0.25 & 0.25 & 0.15 & 0.05
\end{array}\right]
\end{aligned}
$$

Using the $M(\cdot,+)$ fuzzy algorithm to perform the synthesis operation, we get:

$$
\begin{aligned}
& R_{11}=W_{11} \cdot R_{11}=(0.3070,0.3446,0.3484)\left[\begin{array}{ccccc}
0.15 & 0.2 & 0.3 & 0.25 & 0.1 \\
0.1 & 0.3 & 0.35 & 0.25 & 0 \\
0.15 & 0.35 & 0.25 & 0.2 & 0.05
\end{array}\right] \\
& =(0.1328,0.2868,0.2999,0.2326,0.0635)
\end{aligned}
$$


By the same logic, we can get

$$
\begin{aligned}
& B_{12}=W_{12} \cdot R_{12}=(0.2504,0.2833,0.2837,0.0990,0.0505) \\
& B_{13}=W_{13} \cdot R_{13}=(0.2565,0.3065,0.1565,0.1000,0.0936) \\
& B_{14}=W_{14} \cdot R_{14}=(0.2482,0.2241,0.3259,0.1759,0.0259) \\
& B_{21}=W_{21} \cdot R_{21}=(0.1365,0.2181,0.3374,0.2181,0.0999) \\
& B_{22}=W_{22} \cdot R_{22}=(0.2482,0.2982,0.2518,0.1000,0.1018) \\
& B_{23}=W_{23} \cdot R_{23}=(0.2500,0.2250,0.2500,0.2000,0.0750) \\
& B_{24}=W_{24} \cdot R_{24}=(0.2614,0.2869,0.2245,0.1256,0.1017)
\end{aligned}
$$

\subsubsection{Second-Level Fuzzy Comprehensive Evaluation}

According to the above first-level fuzzy comprehensive evaluation results, the second-level fuzzy comprehensive synthesis operation is also carried out by using the $M(\cdot,+)$ synthesis algorithm.

$$
\begin{aligned}
& B_{1}=W_{1} \cdot R_{1}=W_{1}\left[\begin{array}{c}
B_{11} \\
B_{12} \\
B_{13} \\
B_{14}
\end{array}\right]= \\
& (0.2084,0.2916,0.2500,0.2500) \\
& \begin{array}{llllll}
0.1328 & 0.2868 & 0.2999 & 0.2326 & 0.0635
\end{array} \\
& \begin{array}{lllllll}
0.2504 & 0.2833 & 0.2837 & 0.099 & 0 & 0.0505
\end{array} \\
& \begin{array}{llllll}
0.2565 & 0.3065 & 0.3065 & 0.100 & 0 & 0.0935
\end{array} \\
& \begin{array}{lllllll}
0.2482 & 0.2241 & 0.3259 & 0.1759 & 0.0259
\end{array} \\
& =(0.2269,0.2750,0.2518,0.1463,0.0578)
\end{aligned}
$$

By the same logic, we can get

$$
\begin{aligned}
& B_{2}=W_{2} \cdot R_{2}=W_{2}\left[\begin{array}{c}
B_{21} \\
B_{22} \\
B_{23} \\
B_{24}
\end{array}\right]
\end{aligned}
$$

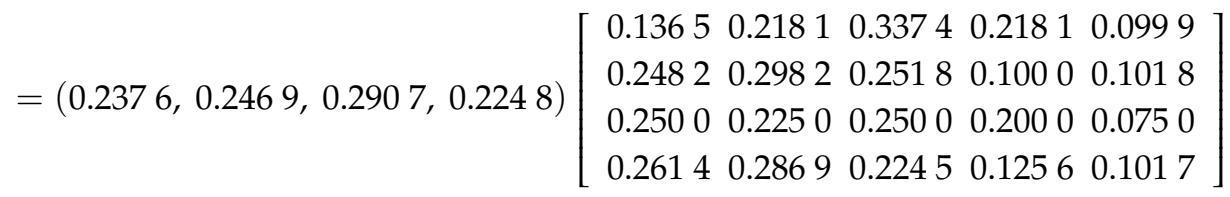

$$
\begin{aligned}
& =(0.2252,0.2553,0.2655,0.1628,0.0935)
\end{aligned}
$$

\subsubsection{Third-Level Fuzzy Comprehensive Evaluation}

Based on the above results, the effectiveness evaluation set of the financing platform operation of the buildings energy saving transformation can be obtained as follows:

$$
\begin{aligned}
& B=W \cdot R=(0.4722,0.5278)\left[\begin{array}{llllll}
0.2269 & 0.275 & 0 & 0.2518 & 0.1463 & 0.0578 \\
0.2252 & 0.2553 & 0.2655 & 0.1628 & 0.0935
\end{array}\right] \\
& =(0.2261,0.1914,0.2583,0.1541,0.0747)
\end{aligned}
$$

\subsection{Comprehensive Judgment of Evaluation Results}

According to the evaluation result $\mathrm{B}$, the factors in the evaluation set $\mathrm{V}$ are quantified and assigned to $100,80,60,40$, and 20 respectively. The weighted average formula is $V=0.2260 \times 100+0.2646 \times$ $80+0.2590 \times 60+0.1550 \times 40+0.0766 \times 20=67.04$.

Furthermore, the fuzzy comprehensive evaluation values of all levels of indicators are calculated, and the fuzzy evaluation values of third grade index under second grade index are obtained. $V_{11}=$ 
64.792, $V_{12}=69.096, V_{13}=63.6535, V_{14}=69.856, V_{21}=62.064, V_{22}=69.82, V_{23}=67.5, V_{24}=$ 69.62. Among them, the scores of $V_{11}, V_{13}$ and $V_{21}$ are all lower than the comprehensive evaluation value.

\section{Discussion}

The effectiveness evaluation result of the financing platform operation for buildings energy saving transformation in Beijing was 67.04, which was between "average" and "good" and inclined to "average". Judging from the evaluation results, although the financing platform has achieved certain results, from the perspective of the overall development of the buildings energy saving transformation market, the platform operation effect is not significant, and there is still much room for optimization. According to the actual situation of the buildings energy saving transformation market development, the operation of the financing platform is in the stage of continuous exploration, the demand for the financing platform is also in the stage of continuous development, and the evaluation results are basically consistent with the actual situation of the platform operation.

According to the above research results can be obtained, to improve the level of buildings energy saving transformation market development and financing platform operation effect, can run to improving the systematization of operating objectives and the coordination of operation process two aspects promote effectiveness, from improving the enthusiasm of owners' energy saving enthusiasm to save energy to enhance the effectiveness of operation subject behavior. Specific optimization suggestions are as follows:

1. Improve the information management system and standardize the platform-operating environment. First, develop an information sharing system to make the financing platform an interactive channel and resource-sharing platform for energy saving information. The energy saving information is more timely and accurate feedback to all participants. Under the integration of resources, the financing platform becomes the cooperation medium between the owners and ESCOs. Secondly, establish an information rating system to break the market information asymmetry and reduce the information status difference between the owners and ESCOs. Owners can better understand ESCO credit information and save on the cost of evaluating corporate credit. ESCO can reach deals with owners based on lower costs, increase trust between subjects, and lay the foundation for cooperation. Finally, establish a standardized management and monitoring system for transaction information to ensure the fairness and order of the project financing transaction market, help to create a cooperative environment of mutual trust, and attract more participants to actively participate in the platform construction. Through the information management system, improve market transparency and create a good market competition environment.

2. Enhance the owner's enthusiasm for energy saving and expand the scale of platform transactions. The owner is the subject of buildings energy saving transformation and provides endogenous power for market development. That is to say, the demand of the owner determines the market size. First, the government should continuously strengthen the implementation of incentive policies, provide more powerful external support for the owners to implement energy saving transformation, avoids failure of the owners to worry about the investment due to excessive transformation costs, and guide more owners to participate in the construction of the platform. Thereby expanding the source of funds and playing a greater role in the financing platform. Second, innovative financing products, such as future earnings securitization, carbon trading, energy-saving income bonds, etc. will expand the scale of platform trading. Deeply understand market demand, promote the diversification of platform functions, achieve scale effect, promote platform development, and improve the success rate of financing. Thirdly, change the owner's consumption concept and enhance the owner's social responsibility consciousness. Owners should actively respond to the call of the national low-carbon policy, change consumption concepts, establish a green low-carbon consumption concept, and enhance social responsibility awareness.

3. Optimizing the systematization of operational objectives is in line with the development trend of the platform. First of all, we should pay attention to the impact of changes in national policy 
environment, the changes of demand of the main body of operation, the level of development of related industries, and energy saving technological innovations on the overall development of the platform. According to those, the optimization system is adjusted to adapt to the dynamic development characteristics of the market. Secondly, from the perspective of improving the system of optimization objectives, we can improve the degree of inter-organizational information interaction, enhance the efficiency of organizational management and the consistency of optimization objectives among the subjects by building an energy saving management information exchange platform. Finally, pay attention to the optimization of links, in-depth market research, feedback of optimization effect, to avoid occurrence of optimization process segmentation.

\section{Conclusions}

In this paper, from the perspective of the effectiveness of operation mechanism implementation and the effectiveness of operation subject's behavior for building energy saving transformation market, considering factors such as platform organization and management efficiency, target consistency, information sharing degree, establishing an evaluation index system for operation effectiveness of existing building energy saving transformation financing platform, analyzing the interaction between indicators, using ANP to determine the weight of indicators, and combine qualitative and quantitative analysis, building a multi-level fuzzy comprehensive evaluation model. According to the results of an empirical study, on the basis of Section 5. Discussion, the following suggestions are put forward to provide theoretical reference for optimizing the buildings energy saving transformation financing platform and promote the development of buildings energy saving transformation market in China.

1 Improve the cooperation between subjects and improve operation efficiency of the platform. The operation of financing platform needs to be based on a certain relationship framework. In order to optimize the subject' cooperation relationship, it is necessary to strengthen the level of information sharing among the platform operators, such as establish the information exchange platform, the information sharing mechanism and feedback mechanism, so as to improve the trust between the subjects and lay the foundation for their cooperation. At the same time, corresponding management policies should also be formulated for the stability of the cooperation between the subjects to ensure the stability and long-term of the cooperation, such as guarantee mechanism, reputation rating mechanism, etc. It can also help to optimize the institutionalization and legalization of cooperative relations through other ways.

2 Pay attention to the formulation and implementation of financing guarantee policies for building energy saving transformation. Because of the differences in the characteristics and laws of different financing subjects in economic activities, it is necessary for the state to establish buildings energy saving transformation project financing guarantee policy system from system level. On the one hand, the government should improve existing laws and regulations and basic policy planning, establish specific safeguard measures and policy evaluation methods, and create a good environment for project financing. On the other hand, we should strengthen the application of insurance strategy. Through the establishment of perfect insurance policies, the implementation of various insurance strategies, according to the different nature and types of enterprises to develop targeted insurance strategies, reduce the risk coefficient of project financing failure. According to the different nature and types of enterprises, government should make targeted insurance strategies to reduce the risk coefficient of project financing failure. This can not only improve the cost-effectiveness of project financing, but also ensure that investors can safely invest the funds into the financing platform, and provide more sufficient financial support for the existing building energy saving transformation projects.

3 Strengthen the capital management of buildings energy saving transformation financing platform, and improve the cost-effectiveness of project financing. After the EPC project is completed, the financing platform shall repay the principal and interest to the investors in time according to relevant contract, so as to improve social reputation of the financing platform. At the same time, 
the financing platform should also strengthen management of the asset pool, determine the cash flow during project operation, strengthen the management of idle funds, and take effective measures to ensure the maintenance and appreciation of the invested capital through the energy measurement and audit of buildings energy saving transformation project.

Author Contributions: Conceptualization, H.G. and Y.Z.; visualization, W.Q.; methodology, W.Q. and Y.Z.; software, W.Q.; data curation, W.Q. and Y.Z.; writing-original draft preparation, W.Q.; writing-review and editing, W.Q.; supervision, H.G. All authors have read and agreed to the published version of the manuscript.

Funding: This research was funded by the National Natural Science Foundation of China (71573188), Late-stage Subsidy Project of Humanities and Social Sciences of the Education Department of China (16JHQ031), Social Science Planning Later Project of Tianjin Province of China (TJGLHQ1403), Higher Education Innovation Team of Tianjin (TD13-5006).

Acknowledgments: The acquisition of data is a complex process in this study. The authors are grateful to all the respondents and industry experts for their participation. In addition, we appreciate editors and anonymous reviewers for the invaluable comments and suggestions that helped in improving this paper.

Conflicts of Interest: The authors declare no conflict of interest.

\section{References}

1. International Energy Agency. Word Energy Outlook China Special Report; Petroleum Industry Press: Beijing, China, 2017; Volume 1, pp. 14-17.

2. Lee, M.; Park, H.; Noh, J. Promoting energy efficiency financing and ESCOs in developing countries: Experiences from Korean ESCO business. J. Clean. Prod. 2003, 11, 651-657. [CrossRef]

3. Zisopoulou, K.; Karalis, S.; Koulouri, M.-E.; Pouliasis, G.; Korres, E.; Karousis, A.; Triantafyllopoulou, E.; Panagoulia, D.G. Recasting of the WEF Nexus as an actor with a new economic platform and management model. Energy Policy 2018, 119, 123-139. [CrossRef]

4. Zisopoulou., K.; Panagoulia, D. Solar Power: A new mathematical definition and theoretical proof it is a Green Public Good. Green Financ. 2019, 1, 312-327. [CrossRef]

5. Hayati, H.; Sayadi, M. Impact of tall buildings in environmental pollution. IAEES 2012, 1, 8-11.

6. Yuan, C.; Ng, E.; Norford, L. Improving air quality in high-density cities by understanding the relationship between air pollutant dispersion and urban morphologies. Build. Environ. 2014, 71, 245-258. [CrossRef]

7. Rodriguez, N.; Sebastian, E. Role of particulate matter from vehicle exhaust on porous building stones (limestone) sulfation. Sci. Total Environ. 1996, 187, 79-91. [CrossRef]

8. Sarkar, A.; Singh, J. Financing energy efficiency in developing countries-lessons learned and remaining challenges. Energy Policy 2010, 38, 5560-5571. [CrossRef]

9. Labanca, N.; Suerkemper, F.; Bertoldi, P. Energy efficiency services for residential buildings: Market situation and existing potentials in the European Union. J. Clean. Prod. 2015, 109, 284-295. [CrossRef]

10. Thollander, P.; Backlund, S.; Trianni, A.; Cagno, E. Beyond barriers-A case study on driving forces for improved energy efficiency in the foundry industries in Finland, France, Germany, Italy, Poland, Spain and Sweden. Appl. Energy 2013, 111, 636-643. [CrossRef]

11. Goldman, C.; Hopper, N.; Osborn, J. Review of US ESCO industry market trends: An empirical analysis of project data. Energy Policy 2005, 33, 387-405. [CrossRef]

12. Marechal, F.; Favrat, D.; Jochem, E. Energy in the perspective of the sustainable development: The $2000 \mathrm{~W}$ society challenge. Resour. Conserv. Recycl. 2005, 44, 245-262. [CrossRef]

13. Sebi, C.; Nadel, S.; Schlomann, B.; Steinbach, J. Policy strategies for achieving large long-term savings from retrofitting existing buildings. Energy Eff. 2019, 12, 89-105. [CrossRef]

14. Gouldson, A.; Kerr, N.; Millward, H.J. Innovative financing models for low carbon transitions: Exploring the case for revolving funds for domestic energy efficiency programmes. Energy Policy 2015, 86, 739-748. [CrossRef]

15. Meijer, F.; Itard, L.; Sunikka-Blank, M. Comparing European residential building stocks: Performance, renovation and policy opportunities. Build. Res. Inf. 2009, 37, 533-551. [CrossRef]

16. Blengini, G.A.; Di, C.T. Energy-saving policies and low-energy residential buildings: An LCA case study to support decision makers in Piedmont (Italy). Int. J. Life Cycle Assess. 2010, 15, 652-665. [CrossRef] 
17. Wang, X.; Lu, M.; Mao, W. Improving benefit-cost analysis to overcome financing difficulties in promoting energy-efficient renovation of existing residential buildings in China. Appl. Energy 2015, 141, 119-130. [CrossRef]

18. Bjorneboe, M.G.; Svendsen, S.; Heller, A. Initiatives for the energy renovation of single-family houses in Denmark evaluated on the basis of barriers and motivators. Energy Build. 2018, 167, 347-358. [CrossRef]

19. Kragh, J.; Rose, J. Energy renovation of single-family houses in Denmark utilising long-term financing based on equity. Appl. Energy 2011, 88, 2245-2253. [CrossRef]

20. Gillich, A. Grants versus financing for domestic retrofits: A case study from efficiency maine. Sustainability 2013, 5, 2827-2839. [CrossRef]

21. Economidou, M.; Zangheri, P.; Mueller, A.; Kranzl, L. Financing the renovation of the cypriot building stock: An assessment of the energy saving potential of different policy scenarios based on the invert. Energies 2018, 11, 3071. [CrossRef]

22. Marino, A.; Bertoldi, P.; Rezessy, S.; Boza-Kiss, B. A snapshot of the European energy service market in 2010 and policy recommendations to foster a further market development. Energy Policy 2011, 39, 6190-6198. [CrossRef]

23. Robinson, M.; Varga, L.; Allen, P. An agent-based model for energy service companies. Energy Convers. Manag. 2015, 94, 233-244. [CrossRef]

24. Kilic, H.S.; Zaim, S.; Delen, D. Selecting “The Best" ERP system for SMEs using a combination of ANP and PROMETHEE methods. Expert Syst. Appl. 2015, 42, 2343-2352. [CrossRef]

25. Kahraman, C.; Onar, S.C.; Oztaysi, B. Fuzzy multicriteria decision-making: A literature review. Int. J. Comput. Intell. Syst. 2015, 8, 637-666. [CrossRef]

26. Saaty, T.L. The modern science of multicriteria decision making and its practical applications: The AHP/ANP approach. Oper. Res. 2013, 61, 1101-1118. [CrossRef]

27. Buyukozkan, G.; Guleryuz, S. An integrated DEMATEL-ANP approach for renewable energy resources selection in Turkey. Int. J. Prod. Econ. 2016, 182, 435-448. [CrossRef]

28. Yuksel, I.; Dagdeviren, M. Using the analytic network process (ANP) in a SWOT analysis-A case study for a textile firm. Inf. Sci. 2007, 177, 3364-3382. [CrossRef]

29. Dagdeviren, M. Decision making in equipment selection: An integrated approach with AHP and PROMETHEE. J. Intell. Manuf. 2008, 19, 397-406. [CrossRef]

30. Yuksel, I.; Dagdeviren, M. Using the fuzzy analytic network process (ANP) for Balanced Scorecard (BSC): A case study for a manufacturing firm. Expert Syst. Appl. 2010, 37, 1270-1278. [CrossRef]

31. Ozaki, T.; Lo, M.C.; Kinoshita, E. Decision-making for the best selection of suppliers by using minor ANP. J. Intell. Manuf. 2012, 23, 2171-2178. [CrossRef]

32. Cheng, E.W.L.; Li, H. Application of ANP in process models: An example of strategic partnering. Build. Environ. 2007, 42, 278-287. [CrossRef]

33. Malmir, M.; Zarkesh, M.M.K.; Monavari, S.M.; Jozi, S.A.; Sharifi, E. Analysis of land suitability for urban development in Ahwaz County in southwestern Iran using fuzzy logic and analytic network process (ANP). Environ. Monit. Assess. 2016, 188, 447. [CrossRef] [PubMed]

34. Cai, W.; Dou, L.; Si, G.; Cao, A.; He, J.; Liu, S. A principal component analysis/fuzzy comprehensive evaluation model for coal burst liability assessment. Int. J. Rock Mech. Min. Sci. 2016, 81, 62-69. [CrossRef]

35. Wang, H.; Wang, J.; Shi, B. Model and application of green industry evaluation based on fuzzy control. J. Intell. Fuzzy Syst. 2015, 29, 2489-2494. [CrossRef]

36. Wang, M.; Niu, D. Research on project post-evaluation of wind power based on improved ANP and fuzzy comprehensive evaluation model of trapezoid subordinate function improved by interval number. Renew. Energy 2019, 132, 255-265. [CrossRef]

37. Gebrehiwet, T.; Luo, H. Risk level evaluation on construction project lifecycle using fuzzy comprehensive evaluation and TOPSIS. Symmetry 2019, 11, 12. [CrossRef]

38. Xu, Y.; Yeung, J.; Chan, A. Developing a risk assessment model for PPP projects in China-A fuzzy synthetic evaluation approach. Autom. Constr. 2010, 19, 929-943. [CrossRef]

39. Liu, G.; Zheng, S.; Xu, P. An ANP-SWOT approach for ESCOs industry strategies in Chinese building sectors. Renew. Sustain. Energy Rev. 2018, 93, 90-99. [CrossRef]

40. Zhu, J.; Chen, Z.; Sun, L. A method of construction of index system for highway maintenance management. Proced. Soc. Behav. Sci. 2013, 96, 1593-1602. [CrossRef] 
41. Zhou, J.; Bai, Z.; Sun, Z. A hybrid approach for safety assessment in high-risk hydropower-construction-project work systems. Saf. Sci. 2014, 64, 163-172. [CrossRef]

42. Jharkharia, S.; Shankar, R. Selection of logistics service provider: An analytic network process (ANP) approach. Omega Int. J. Manag. Sci. 2007, 35, 274-289. [CrossRef]

43. Buyukozkan, G.; Cifci, G. A novel hybrid MCDM approach based on fuzzy DEMATEL, fuzzy ANP and fuzzy TOPSIS to evaluate green suppliers. Expert Syst. Appl. 2012, 39, 3000-3011. [CrossRef]

44. He, F.; Chen, X. Credit networks and systemic risk of Chinese local financing platforms: Too central or too big to fail?-Based on different credit correlations using hierarchical methods. Phys. A 2016, 461, 158-170. [CrossRef]

45. Agyekumhene, C.; Vries, J.R. Digital platforms for smallholder credit access: The mediation of trust for cooperation in maize value chain financing. NJAS Wagening. J. Life Sci. 2018, 86-87, 77-88. [CrossRef]

46. Gerrish, T.; Ruikar, K.; Cook, M.; Johnson, M.; Phillip, M.; Lowry, C. BIM application to building energy performance visualisation and management: Challenges and potential. Energy Build. 2017, 144, 218-228. [CrossRef]

47. Guo, H.; Qiao, W.; Liu, J. Dynamic feedback analysis of influencing factors of existing building energy-saving renovation market based on system dynamics in China. Sustainability 2019, 11, 273. [CrossRef]

48. Kim, J.J. Economic analysis on energy saving technologies for complex manufacturing building. Resour. Conserv. Recycl. 2017, 123, 249-254. [CrossRef]

49. Martinaitis, V.; Rogoza, A.; Bikmaniene, I. Criterion to evaluate the "twofold benefit" of the renovation of buildings and their elements. Energy Build. 2004, 36, 3-8. [CrossRef]

50. Rouyendegh, B.D. Developing an integrated ANP and intuitionistic fuzzy TOPSIS model for supplier selection. J. Test. Eval. 2015, 43, 3. [CrossRef]

51. Wang, X.; Liu, Z.; Cai, Y. A rating based fuzzy analytic network process (F-ANP) model for evaluation of ship maneuverability. Ocean Eng. 2015, 106, 39-46. [CrossRef]

52. Bakeshlou, E.A.; Khamseh, A.A.; Asl, M.A.G. Evaluating a green supplier selection problem using a hybrid MODM algorithm. J. Intell. Manuf. 2017, 28, 913-927. [CrossRef]

53. Ervural, B.C.; Zaim, S.; Demirel, O.F.; Aydin, Z.; Delen, D. An ANP and fuzzy TOPSIS-based SWOT analysis for Turkey's energy planning. Renew. Sustain. Energy Rev. 2018, 82, 1538-1550. [CrossRef]

54. Xu, P.; Chan, E.H.W.; Visscher, H.J. Sustainable building energy efficiency retrofit for hotel buildings using EPC mechanism in China: Analytic Network Process (ANP) approach. J. Clean Prod. 2015, 107, 378-388. [CrossRef] 